\section{New Officers and Board Members Elected}

At the annual meeting of the American Board of Family Practice (ABFP), the Board elected new officers to serve during the upcoming year. These positions are president, vice president, treasurer, and member-at-large. Each new officer has served as a Board member for at least 3 years in a variety of different capacities. Three new Board members were also selected at this meeting.

As the ABFP enters its 35 th year of service to the specialty, it can directly trace its ability to maintain high standards for its policies and examinations to the efforts of its outstanding Board of Directors. James Puffer, MD, Executive Director of the ABFP, stated, "Our Board members are essential to our success. Each is selected for his or her ability to bring unique perspectives and experience to help us examine both our policies and the issues that relate to family physicians today.”

The Board of Directors is responsible for making policy for the ABFP. This effort includes setting quality standards for admission to the examinations, giving final approval of all questions on the examinations, and approving the pass-fail score for the examinations. With more than 70,000 current Diplomates, family medicine is the second largest medical specialty in the United States.

The ABFP Board of Directors consists of 15 members selected by the Board. There are 10 family physicians, 5 of whom are nominated through the American Academy of Family Physicians (AAFP), and 5 are nominated by organizations outside the Board or by the Board. In addition, there are representatives from 5 other specialties, including internal medicine, surgery, pediatrics, obstetrics-gynecology, and psychiatry-neurology. Each Board member serves a 5 -year term. All members of the Board of Directors are physicians and must be certified throughout their term on the Board.

\section{New Officers}

New officers were elected at the annual meeting. Each has been extremely active in serving on committees during his or her tenure on the Board and brings a unique perspective based on experience from their practice. The new officers were asked to

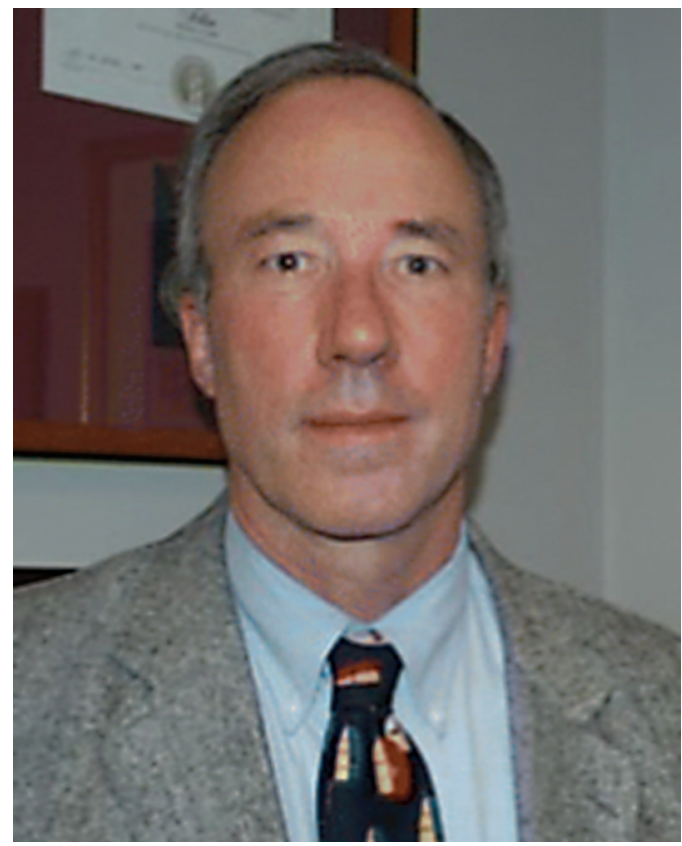

Figure 1. Thomas E. Norris, MD, President

reflect on what their service on the Board means to them.

\section{Thomas E. Norris, MD, President}

Dr. Norris (Figure 1) is Vice Dean for Academic Affairs and Professor of Family Medicine at the University of Washington School of Medicine. He is also an Adjunct Professor in Biomedical Informatics (Medical Education), Medicine, and Health Services. In addition, he currently serves as Executive Director and Medical Director of the UW Physician's Network.

"My background is in both the practice world and academic world. Due to this dual perspective, I can see the importance of the Board's work from the standpoint of both the practicing physician and the academic physician. The public expects family doctors to practice Family Medicine of the highest quality with the highest levels of patient safety, and Family Physicians expect the ABFP to offer a certification/recertification program that is fair, practical, useful, and efficient. I am committed to meeting both of these goals."

Thomas L. Schwenk, MD, Vice President

Dr. Schwenk (Figure 2) is Professor and Chair of the Department of Family Medicine, University of 


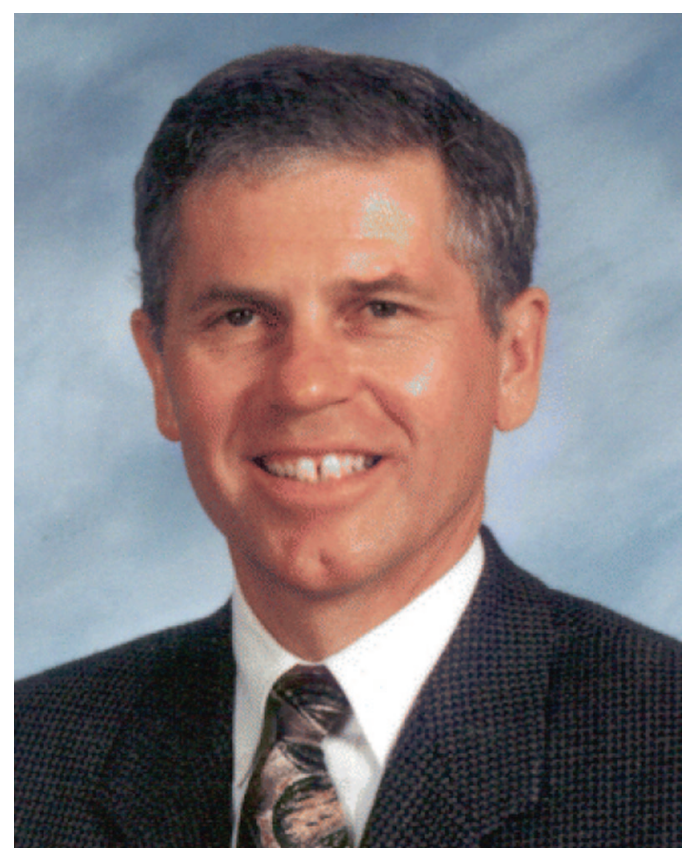

Figure 2. Thomas L. Schwenk, MD, Vice President

Michigan. He stated, "I have always valued the contributions of the ABFP Board in setting standards for the specialty and helping family physicians meet those standards. I will continue to use my clinical and academic experience in supporting and enhancing those critical activities. I have always tried to represent the values that define family practice, while dedicating my efforts to finding ways in which to improve the linkages between the academic and clinical worlds. In short, I want to work to improve the quality of family practice education and practice, so as to enhance the credibility and influence of the specialty."

Dr. Schwenk continued, "I am particularly excited to be involved with the ABFP at a time when we are exploring new approaches to learning, evaluation, and certification. The Maintenance of Certification (MC-FP) process, although still controversial for some, represents a major advance in how we can help family physicians learn as well as portray their skill and expertise to the public we all serve."

\section{Frank L. Kane, MD, Treasurer}

Dr. Kane (Figure 3) has been in private practice for the last 19 years and is currently a member of the Skylands Medical Group in Newton, New Jersey.

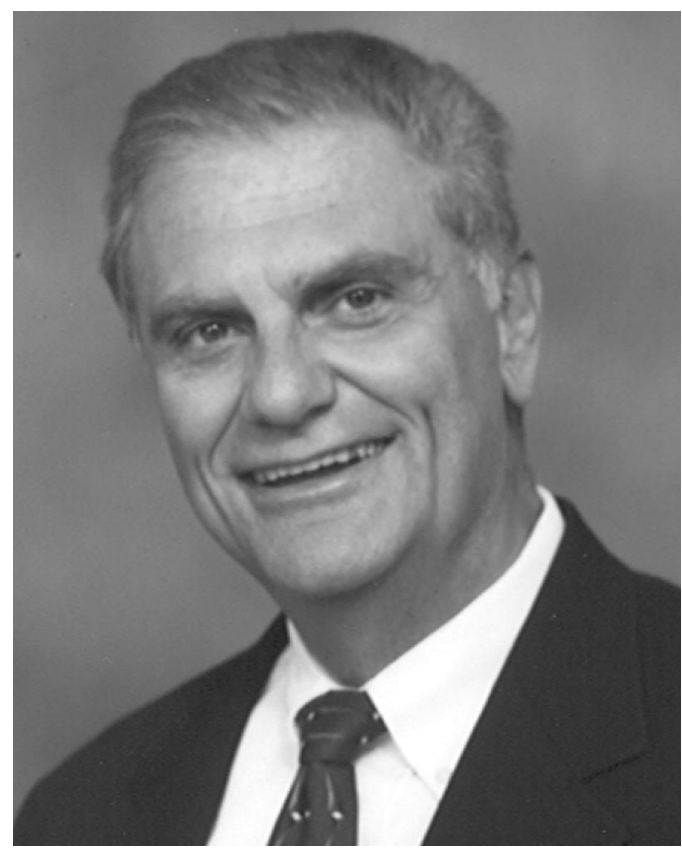

Figure 3. Frank L. Kane, MD, Treasurer

He serves as a Clinical Assistant Professor in the Department of Family Practice at the Robert Wood Johnson Medical School and the New Jersey Medical School. He is Past Chairman of the Department of Family Practice at St. Clares Hospital in Denville, New Jersey. Dr. Kane is very active in his service locally, regionally, and nationally for family medicine through his affiliation with the American Academy of Family Physicians (AAFP). $\mathrm{He}$ is also the Past President of the New Jersey Academy of Family Physicians and the New Jersey Academy of Family Physicians Foundation. At the local level, Dr. Kane coaches youth football and serves as team physician for 2 area high schools. Recently, he had articles relating to child development and Alzheimer disease published in Newsweek and Reader's Digest, respectively.

Dr. Kane stated, "I have always been passionate about family medicine. I began my training as a physician assistant before entering medical school. Eleven years after graduating, I became President of the New Jersey Academy of Family Physicians, and my dedication to the specialty continued to intensify from there." He added, "I am honored to be part of a group that continues to maintain the high grade of qualifications established by the American Board of Family Practice and Dr. Nicholas J. Pisacano 35 years ago.” 


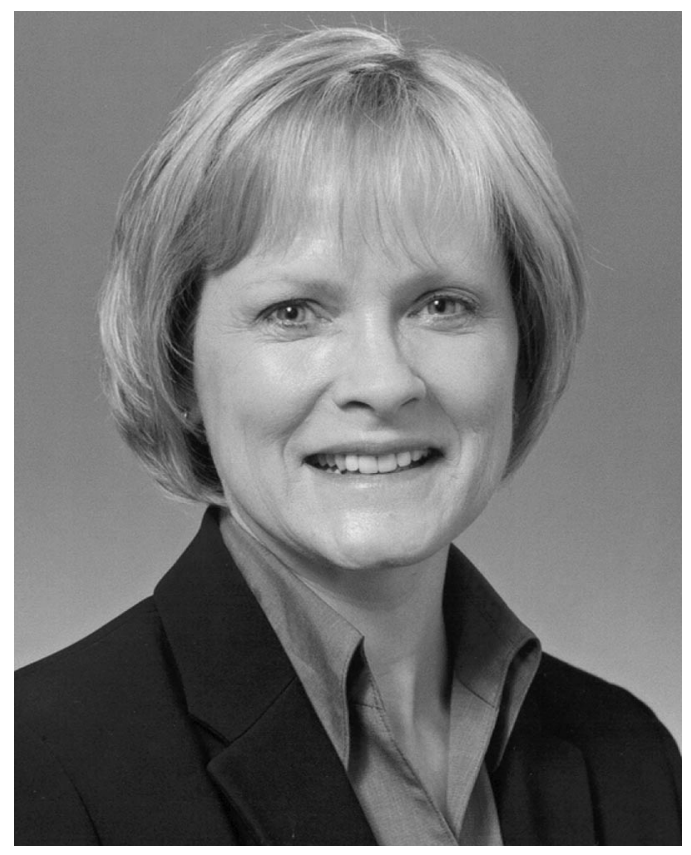

Figure 4. Deborah G. Haynes, MD, Member-at-Large

\section{Deborah G. Haynes, MD, Member-at-Large}

Dr. Haynes (Figure 4) devotes $95 \%$ of her professional time to her private practice with Preferred Medical Associates Northeast in Wichita, Kansas. She is also Chair of the Board of this organization. She cares for patients ranging in age from newborns to 102 years and averages more than 100 patient visits per week. Before entering private practice, she was on the teaching staff at St. Joseph's Hospital Family Practice Residency Program (now Via Christi Regional Medical Center). Today, she serves on their Board of Directors. Dr. Haynes also serves as Clinical Associate Professor, teaching residents and medical students at the University of Kansas School of Medicine, and is a member of the teaching staff at Wesley Medical Center in Wichita, Kansas.

She stated, "The ABFP has a rich history of commitment to academic integrity and excellence, and it has set the standard for time-limited certificates. The future of Family Practice depends on a strong foundation of teaching, clinical practice, and certification of our abilities. The founders of the Family Practice movement understood the need for physicians to practice medicine with both science and care. I look forward to continuing to carry out those principles."

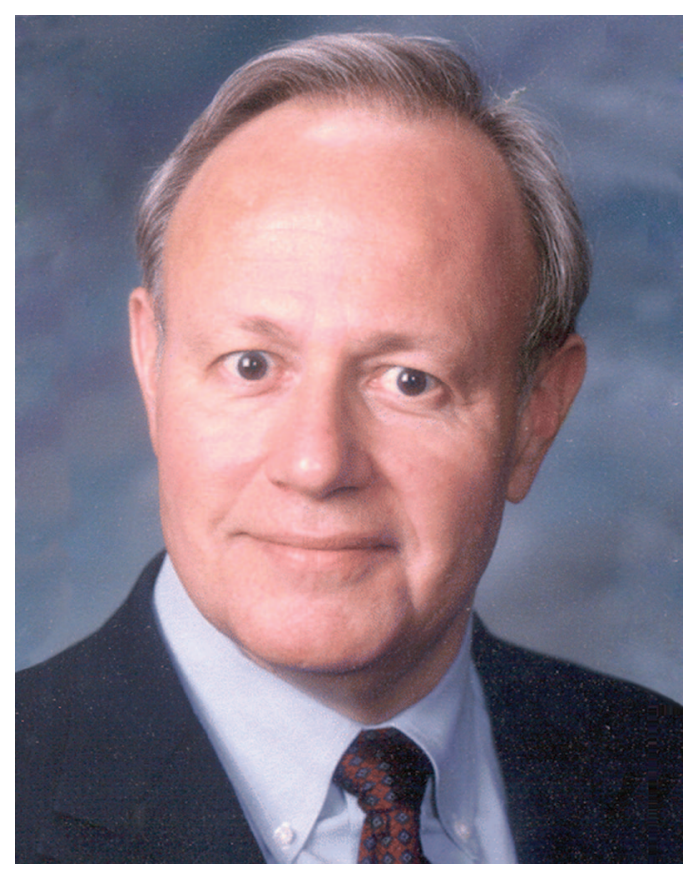

Figure 5. Ross Black II, MD

\section{New Board Members Selected}

Three new Board members were selected at the annual meeting. Each brings to the Board a tremendous amount of experience and a strong commitment to family medicine.

\section{Ross Black II, MD}

Dr. Ross Black II (Figure 5) maintains a full-time practice with Millpond Family Physicians, Inc., in Cuyahoga Falls, Ohio. His practice includes providing care to patients in his office, at a hospital, and at extended care facilities. He also teaches in these settings with residents from three Family Practice Residency programs-Akron General Medical Center, SUMMA Health System, and Barberton Citizens Hospital. He works with medical students at Northeastern Ohio University College of Medicine (NEOUCOM), where he holds an appointment as Clinical Professor. He has been very active in local, regional, and national Family Physician organizations.

"When I was a resident in the early '70s, I was introduced to Dr. Nicholas Pisacano and his philosophy that certification and recertification examinations, along with standardized practice verification, for all Family Physicians would guarantee the future of the specialty. Also at that time, I was fortunate to be a part of the Residency Assistance Program (RAP), which helped establish the quality 


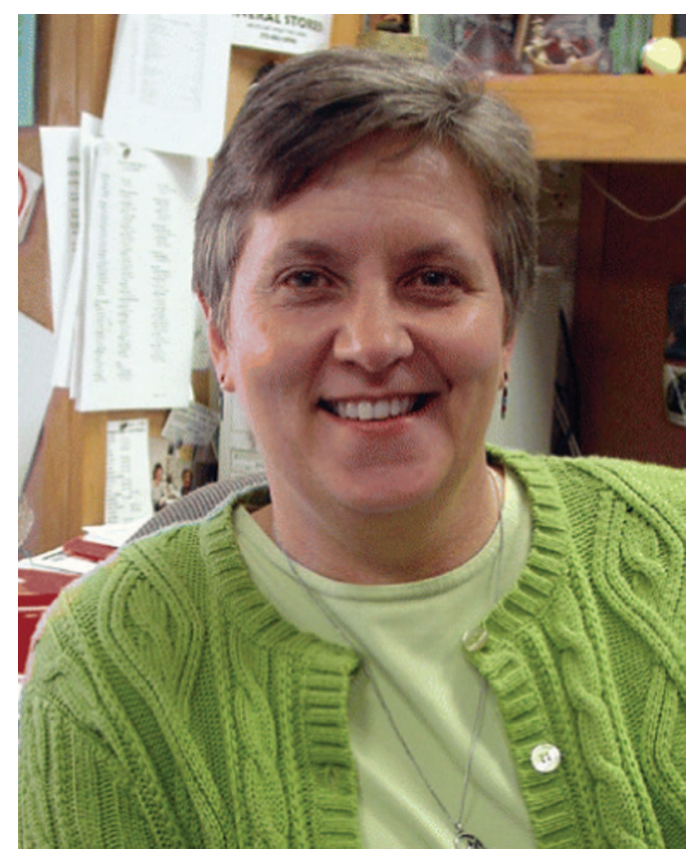

Figure 6. Elizabeth Ann Garrett, MD, MSPH

standards for residency programs that the specialty benefits from today. I find it unique that my career has come full-circle. I am honored to work with others who are just as committed to Dr. Pisacano's philosophy as I am. The challenges facing the $\mathrm{ABFP}$ today are no different from those faced by the Board in 1969. Once again, we find that the future of the specialty depends on the adherence to the highest standards and the delivery of the highest quality of health care."

\section{Elizabeth Ann Garrett, MD, MSPH}

Elizabeth Ann (Betsy) Garrett, MD, MSPH (Figure 6), is Professor of Clinical Family Medicine, Department of Family and Community Medicine, University of Missouri-Columbia School of Medicine. She is Course Director for the Family Medicine Clerkship and serves on the Faculty Affairs Council. She has had significant national family medicine involvement, including serving as President of the Society of Teachers of Family Medicine, 2002 to 2003. She has received a number of awards and honors throughout her career including: STFM President's Award, University of Missouri-Columbia Medical Alumni Association Outstanding Young Physician Award, Golden Apple Award, and Jane Hickman Teacher of the Year Award.

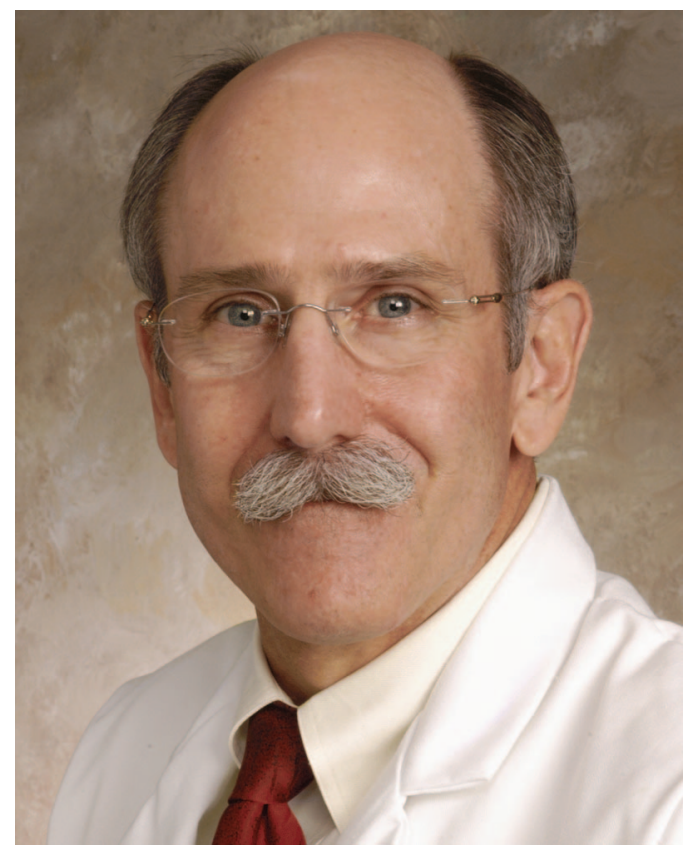

Figure 7. Russell R. Snyder, MD

Dr. Garrett stated, "I am delighted to have this opportunity and privilege to serve our patients and our discipline. This is a critical time in the history of the relationship between physicians and patients; national reports have underscored numerous problems with the health care system. To make the needed changes will require family physicians that are of the highest quality and committed to excellence and reflective practice. The ABFP works to help ensure that we meet these standards and fulfill our sacred trust."

\section{Russell R. Snyder, MD}

Dr. Snyder (Figure 7) dedicated the first 21 years of his career to serving in the United States Air Force (USAF) and Residency Education in Obstetrics and Gynecology. He retired in 1997 as the Chairman of the Department of Obstetrics and Gynecology at Wilford Hall USAF Medical Center. He currently serves in a number of positions, including Associate Professor, Director and Chief, Division of Gynecology and Medical Director, Obstetrics and Gynecology Clinics, Department of Obstetrics and Gynecology, The University of Texas Medical Branch at Galveston; Board of Directors of the American Board of Obstetrics and Gynecology; Chair of the Committee on Scientific Program of the American College of Obstetricians and Gynecologists (ACOG); Past District Chair, Armed Forces District 
of the ACOG; and past member of the Editorial Board for Obstetrics and Gynecology. Dr. Snyder performed his residency in Obstetrics and Gynecology at Wilford Hall USAF Medical Center, Lackland Air Force Base, Texas, and received a Fellowship in Gynecologic and Breast Pathology at the Armed Forces Institute of Pathology, Washington DC.
Dr. Snyder stated, "I am really thrilled to join the ABFP's Board of Directors. I view the ABFP as an organization that is on the cutting edge of Maintenance of Certification and the integration of computer technology in the process of certification/ recertification. I am honored to represent my specialty.” 